\title{
Grain Refinement of AZ31 and AZ61 Mg Alloys through Room Temperature Processing by UP-Scaled High-Pressure Torsion
}

\author{
Takahiro Masuda ${ }^{1,2, *}$ and Zenji Horita ${ }^{1,2}$ \\ ${ }^{1}$ Department of Materials Science and Engineering, Faculty of Engineering, Kyushu University, Fukuoka 819-0395, Japan \\ ${ }^{2}$ WPI, International Institute for Carbon-Neutral Energy Research (WPI-I2CNER), Kyushu University, Fukuoka 819-0395, Japan
}

\begin{abstract}
This study presents application of an up-scaled high-pressure torsion (HPT) process to AZ31 and AZ61 Mg alloys for ultrafine grain refinement. Disks with $30 \mathrm{~mm}$ diameter were processed at room temperature under 6 to $7 \mathrm{GPa}$ using the up-scaled HPT facility with a maximum capacity of $5 \mathrm{MN}$ (500 ton). Microstructural evolution was evaluated by hardness measurement and microscopy observations including tensile testing. The grain size was well refined to $\sim 150 \mathrm{~nm}$ and $\sim 100 \mathrm{~nm}$ at the saturated state for the AZ31 and AZ61 alloys, respectively. Superplastic elongations of $\sim 520 \%$ and $\sim 550 \%$ were then attained in the corresponding alloys when tested in tension at elevated temperatures because of the grain boundary sliding controlled by grain boundary diffusion. Upsizing of the disk sample makes for a chance to extract the tensile specimens at different radial distance within the same disk and therefore the effect of the equivalent strain on the superplastic elongations was effectively evaluated. [doi:10.2320/matertrans.M2018308]
\end{abstract}

(Received September 18, 2018; Accepted February 21, 2019; Published April 5, 2019)

Keywords: severe plastic deformation (SPD), high-pressure torsion, grain refinement, magnesium alloy, superplasticity

\section{Introduction}

It is now well known that processing through severe plastic deformation (SPD) leads to significant grain refinement to submicrometer or nanometer sizes in many metallic materials. ${ }^{1,2)}$ In particular, SPD under high pressure such as high-pressure torsion (HPT) ${ }^{3-5)}$ opens to a chance of nanostructural refinement not only in the metallic materials ${ }^{3,4)}$ but also hard-to-deform materials such as intermetallics, ${ }^{6-11)}$ semiconductors $^{12-19)}$ and ceramics. ${ }^{20-25)}$ The HPT process also provides an opportunity for powder consolidation so that it is possible to increase the rate of powder compaction ${ }^{20}$ ) and to decrease sintering temperature ${ }^{26)}$ or even to synthesize new atomic structured materials. ${ }^{27-30)}$

However, the use of the HPT process is restricted because of the sample size which is generally a disk with a diameter of $10 \mathrm{~mm}$ and a thickness of $1 \mathrm{~mm}$. Upsizing the disk could be feasible with sacrifice of imposed pressure if the machine capacity is the same. Nevertheless, higher pressures at least greater than a few GPa are required for proper holding of a disk without generating slippage between the disk and the anvils. ${ }^{31)}$ Lowering the pressure may also cause breaking the disk or introducing cracks if the disk samples are brittle in nature such as $\mathrm{Mg}$ alloys. In this study, we thus increase the machine capacity to $5 \mathrm{MN}$ (500 ton) to process disks with $30 \mathrm{~mm}$ in diameter so that it is possible to maintain a high imposed pressure up to $7 \mathrm{GPa}$. We will then demonstrate that $\mathrm{Mg}$ alloys are successfully processed at room temperature for grain refinement in such upsized disks.

It should be noted that heating the samples is generally required when they are processed by SPD or heavy deformation for grain refinement. ${ }^{32-38)}$ However, it appears that the constraining of the sample by application of pressure is effective to reduce the processing temperature or to avoid a chance of breaking and cracking. ${ }^{33)}$ Among many reports on the AZ31 alloy using SPD processes as commented by Huang et al., ${ }^{39)}$ studies by Xu et al. ${ }^{40)}$ and Straska et al. ${ }^{41)}$

*Corresponding author, E-mail: masuda@zaiko6.zaiko.kyushu-u.ac.jp appear to be only the reports that successfully processed the AZ31 alloy at room temperature using HPT. Xu et al. ${ }^{40)}$ reported the appearance of superplasticity with a total elongation of $\sim 400 \%$ due to significant grain refinement by the HPT processing. An AZ61 alloy was also processed by HPT at room temperature by Harai et $a l .{ }^{42)}$ and they reported a total elongation of $260 \%$ As will be demonstrated in this study, we also show that the upsized disk exhibits superplasticity with the total elongation of $\sim 520 \%$ for the AZ31 alloy and $\sim 550 \%$ for the AZ61 alloy after processing at room temperature using HPT with the up-scaled (500 ton) capacity. ${ }^{43)}$ We will then demonstrate that the up-scaled HPT process can produce superplasticity through ultrafine-grained structure in $\mathrm{Mg}$ alloys with an enlarged area.

\section{Experimental Procedures}

Commercially extruded AZ31 and AZ61 alloys with nominal compositions of $\mathrm{Mg}-3 \% \mathrm{Al}-1 \% \mathrm{Zn}$ and $\mathrm{Mg}-6 \% \mathrm{Al}-$ $1 \% \mathrm{Zn}$ in mass $\%$, respectively, was received in a form of rod having $30 \mathrm{~mm}$ in diameter. The rod was sliced to disks with $1 \mathrm{~mm}$ thickness using a wire-cutting electrical discharge machine (EDM). The average grain size of the as-received alloy was $\sim 15 \mu \mathrm{m}$ for the AZ31 alloy and $\sim 34 \mu \mathrm{m}$ for the AZ61 alloy. The disks were processed by HPT at room temperature for 2 and 10 turns with a rotation speed of $1 \mathrm{rpm}$ under applied loads of 500 ton and 430 ton corresponding to pressures of $7 \mathrm{GPa}$ for the AZ31 alloy and of $6 \mathrm{GPa}$ for the AZ61 alloy.

Vickers microhardness was measured on the disks with mirror-like surfaces from the center to edge at 8 different radial directions as illustrated in Fig. 1(a). For this hardness measurement, a load of $100 \mathrm{~g}$ was applied for a dwell time of 15 seconds using a Mitutoyo HM-102 hardness tester.

Microstructures of the HPT-processed samples were observed by transmission electron microscopy (TEM) using a Hitachi-8100 at an accelerating voltage of $200 \mathrm{kV}$. For TEM observations, small disks with $3 \mathrm{~mm}$ in diameter were cut as shown in Fig. 1(a) using the EDM so that the center of the 


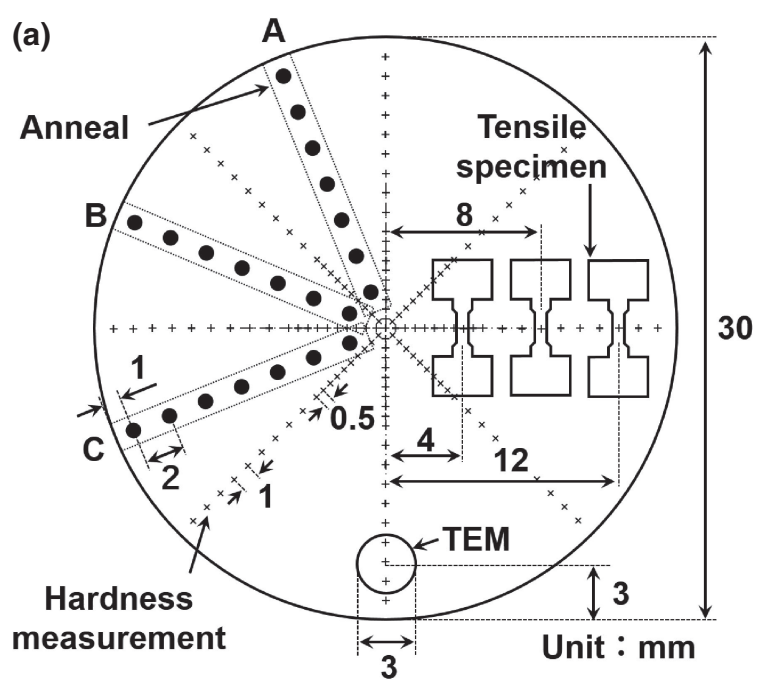

(b)

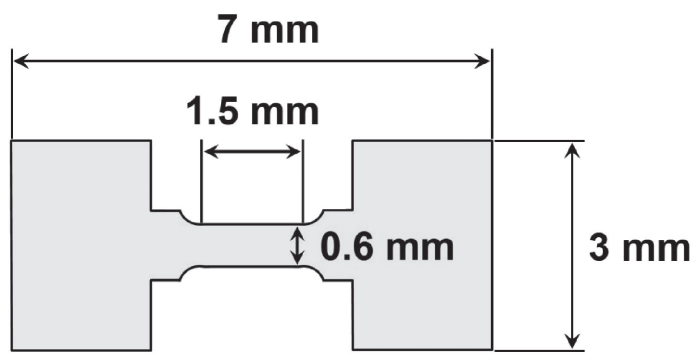

Thickness : $0.7 \mathrm{~mm}$

Fig. 1 (a) Dimensions of HPT disk, sampling locations for tensile testing, transmission electron microscopy (TEM) and annealing, positions for Vickers microhardness measurement, and (b) dimensions of tensile specimen.

TEM disk is located at a position $12 \mathrm{~mm}$ away from the disk center. The $3 \mathrm{~mm}$ disks were mechanically polished to a thickness of $100 \mu \mathrm{m}$ and subjected to twin-jet electropolishing using a solution of $2 \% \mathrm{HClO}_{4}-28 \% \mathrm{C}_{3} \mathrm{H}_{8} \mathrm{O}_{3}-$ $70 \% \mathrm{C}_{2} \mathrm{H}_{5} \mathrm{OH}$ (in vol\%).

Microstructures were also observed by optical microscopy after annealing of the HPT-processed sample. Three pieces of specimens with dimensions of $1 \times 14 \times 0.5 \mathrm{~mm}^{3}$ were cut from the HPT-processed disk along the three different radial directions as illustrated in Fig. 1(a), and were annealed at $623 \mathrm{~K}$ for $1 \mathrm{~h}$ in argon atmosphere. They were polished to a mirror-like surface and were chemically etched using a solution of $4.2 \mathrm{~g} \mathrm{C}_{6} \mathrm{H}_{2}(\mathrm{OH})\left(\mathrm{NO}_{2}\right)_{3}-10 \mathrm{ml} \mathrm{CH} \mathrm{CHOH}_{3} \mathrm{CO} \mathrm{ml}$ $\mathrm{H}_{2} \mathrm{O}-160 \mathrm{ml} \mathrm{C}_{2} \mathrm{H}_{5} \mathrm{OH}$. Optical micrographs were taken at distances of $2,4,6,8,10,12$ and $14 \mathrm{~mm}$ from the disk center.

Tensile specimens with the dimensions shown in Fig. 1(b) were extracted from the HPT-processed disks using the EDM at the same position as the TEM observation $(12 \mathrm{~mm}$ away from the disk center) for each alloy, and they were further extracted at 4 and $8 \mathrm{~mm}$ away from the disk center for the AZ61 alloy as shown in Fig. 1(a). Tensile tests were conducted with three different initial strain rates, $1 \times$ $10^{-4} \mathrm{~s}^{-1}, 3 \times 10^{-4} \mathrm{~s}^{-1}$ and $1 \times 10^{-3} \mathrm{~s}^{-1}$, at two different temperatures, $623 \mathrm{~K}$ and $673 \mathrm{~K}$. Tensile tests were further conducted on the AZ61 alloy with the initial strain rate of $1 \times 10^{-3} \mathrm{~s}^{-1}$ at $473 \mathrm{~K}$.
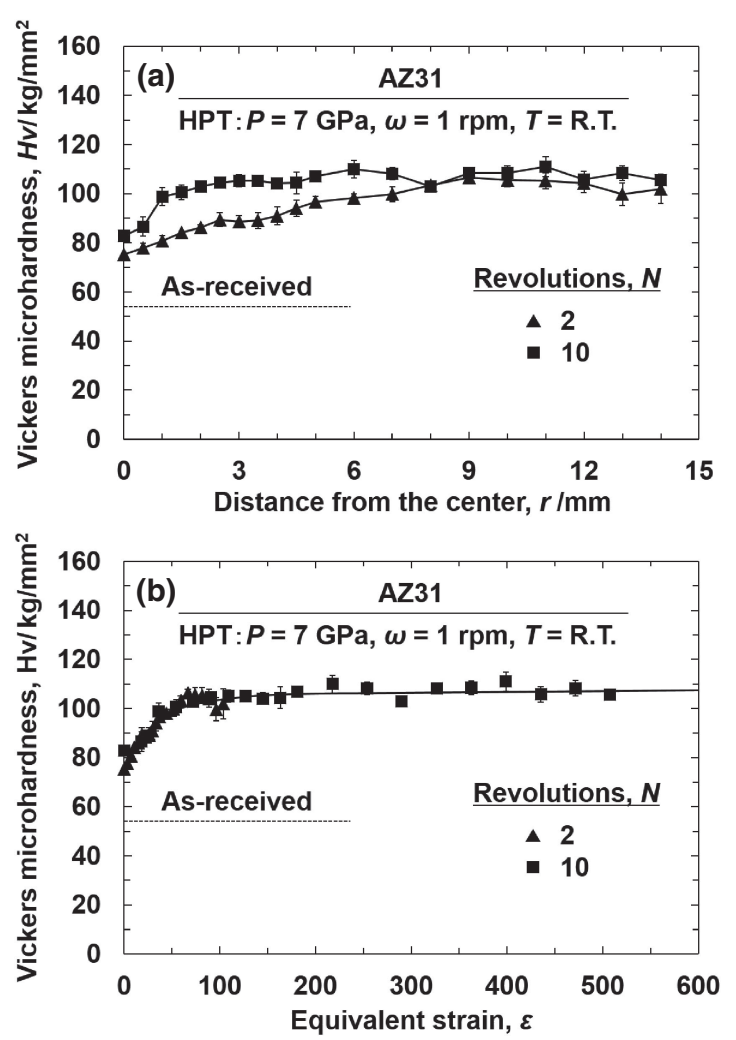

Fig. 2 Vickers microhardness plotted against (a) distance from disk center and (b) equivalent strain for samples processed by HPT through 2 and 10 turns.

\section{Results and Discussions}

\subsection{Hardness measurement of AZ31 alloy}

The variations of Vickers microhardness are plotted in Fig. 2(a) against the distance from the disk center and in Fig. 2(b) against the equivalent strain after processing for $N=2$ and 10 turns at room temperature. The hardness level of the as-received sample is also included in Fig. 2. The von Mises equivalent strain, $\varepsilon$, was calculated using the following equation. ${ }^{4,5)}$

$$
\varepsilon=\frac{2 \pi r N}{\sqrt{3} t}
$$

where $r$ is the distance from the disk center, $N$ is the number of turns and $t$ is the thickness of the disk. These plots clearly show that the hardness increases with increasing the distance from the disk center and thus with increasing the equivalent strain. This behavior is similar to the ones reported in other metals and alloys. ${ }^{44,45)}$ The hardness saturates at the equivalent strain beyond $\sim 80$ with a steady-state level of $\sim 107 \mathrm{Hv}$, where the hardness remains unchanged with straining. These measurements show that the microhardness significantly increases by HPT processing as compared to the initial value of $53 \mathrm{Hv}$ at the as-received state. Huang et al. ${ }^{39)}$ reported that the hardness increased up to $105 \mathrm{Hv}$ at the saturated state for an AZ31 alloy after processing by HPT, whereas $\mathrm{Xu}$ et $a l^{40}{ }^{40}$ reported that the saturated hardness value of $125 \mathrm{Hv}$ by HPT processing. Despite the sample size is the same for both reports, it is not known why the latter is higher than the former but it is most probable that the difference in the saturated hardness level may be attributed to 

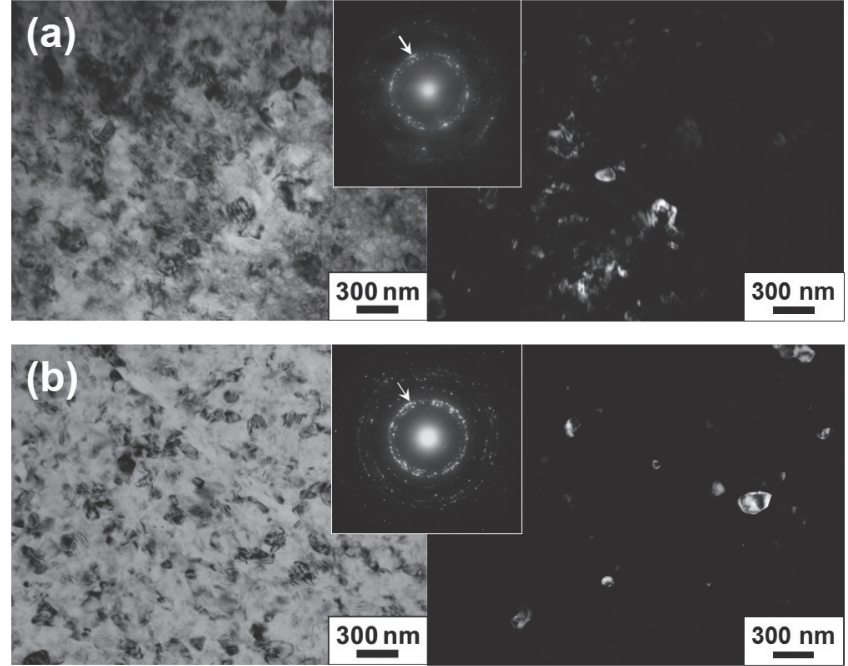

Fig. 3 TEM bright-field images (left), dark-field images (right) and selected area electron diffraction (SAED) patterns (inset) after HPT processing through (a) 2 turns and (b) 10 turns. Arrows in SAED patterns indicate beams for dark-field imaging.

the difference in the composition. Nevertheless, the hardness value at the saturated state achieved in this study by the up-scaled HPT machine can produce almost the same results as processed with the $10 \mathrm{~mm}$ diameter disks. ${ }^{39,40)}$

\subsection{Microstructure after HPT processing of AZ31 alloy}

Figure 3 shows TEM bright-field images (left), dark-field images (right) and the corresponding SAED patterns (center) for the samples processed by HPT for (a) 2 turns and (b) 10 turns under $7 \mathrm{GPa}$ at room temperature. The dark-field image was taken using the diffracted beam indicated by an arrow in the SAED pattern. It is apparent that significant grain refinement occurs even after 2 turns and the grain size is well reduced to the submicron level. Figure 3(b) clearly shows that fine grains with an equiaxed structure having high-angles of misorientation are well developed homogeneously after 10 turns, leading to an average grain size of $\sim 150 \mathrm{~nm}$ as confirmed from the dark-field image. It should be noted that the grain refinement was feasible at room temperature without breaking the samples, and this must be due to the high applied pressure adopted in the HPT processing.

\subsection{Microstructural homogeneity and stability by annealing}

Microstructures of the sample processed for 10 turns were observed by optical microscopy after annealing at $623 \mathrm{~K}$ for 1 hour at positions 4 and $12 \mathrm{~mm}$ apart from the disk center along the three radial directions as illustrated in Fig. 1(a). Figure 4(a) and (b) are typical micrographs showing an equiaxed grain structure with an average grain size of $\sim 6-$ $7 \mu \mathrm{m}$. This was also confirmed at other positions as plotted in Fig. 5 which includes the plots of the grain sizes at 2, 6, 8, 10 and $14 \mathrm{~mm}$ from the disk center. Thus, it is concluded that the homogeneous microstructure was well developed over the areas where the tensile specimens were extracted, and more importantly, it is anticipated that the grain size is still small enough to produce superplasticity.
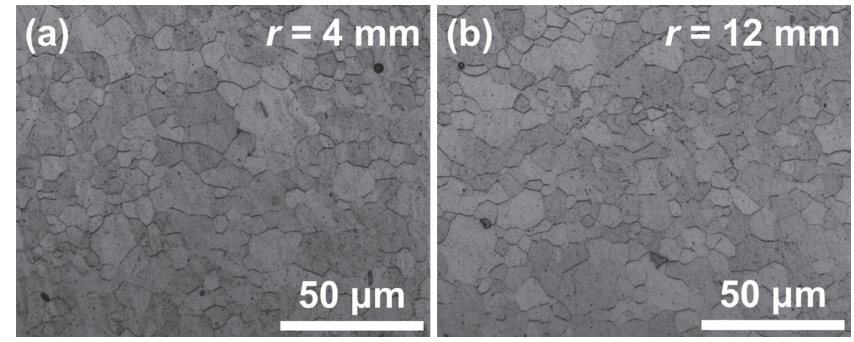

Fig. 4 Optical micrographs obtained at (a) $r=4$ and (b) $r=12 \mathrm{~mm}$ in $\mathbf{B}$ direction shown in Fig. 1(a)

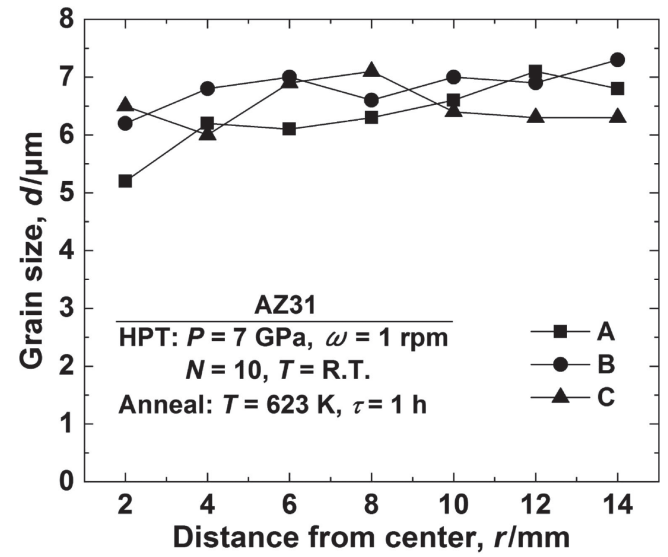

Fig. 5 Average grain size plotted against distance from disk center after HPT processing through 10 turns followed by annealing at $623 \mathrm{~K}$ for $1 \mathrm{~h}$.

\subsection{Deformation behavior of AZ31 alloy}

The results of tensile tests are shown in Fig. 6 and Fig. 7 for the samples processed through $N=2$ and 10 turns, respectively, where the nominal flow stress is delineated against elongation in (a) and the appearance after specimen failure including the one before tensile deformation is shown in (b). As the strain rate decreases and the testing temperature increases, the stress-strain curve becomes smooth with the maximum flow stress lowered. This trend is more prominent in the samples after $N=10$ turns than after $N=2$ turns. The sample appearance after failure in (b) clearly shows that the deformation occurs uniformly throughout the gauge length for all specimens. It should be noted that the values for the total elongation given in (b) are taken from the recording of the stress-elongation curves in (a) and thus the values may include the deformation adjacent to the gage parts.

Figure 8 shows the summary of the total elongation plotted against the initial strain rate. It is clearly shown that the total elongation to failure is higher in the samples processed for $N=10$ turns than $N=2$ turns and it increases as the strain rate decreases and the testing temperature increases. Thus, the superplastic elongation more than $\sim 300 \%$ is attained in most of the samples except the highest strain rate at $623 \mathrm{~K}$. These tensile results demonstrate that it is possible to modify the AZ31 alloy to be superplastic thanks to the grain refinement achieved by HPT processing even at room temperature.

\subsection{Activation energy}

The following equation may be useful to understand the deformation mechanism controlling the deformation flow. ${ }^{46,47)}$ 

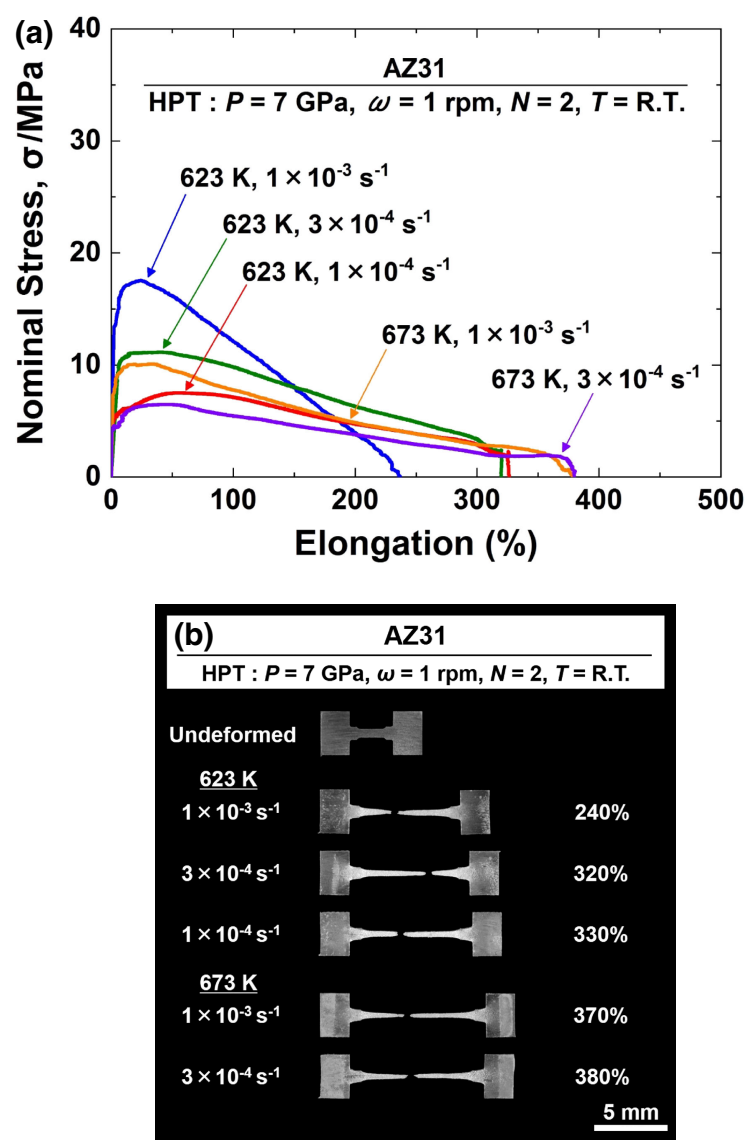

Fig. 6 (a) Nominal stress-elongation curves and (b) appearance of tensile specimens after deformation to failure for samples processed by HPT through 2 turns.

$$
\dot{\varepsilon}=A \frac{G b}{k T} D_{0}\left(\frac{b}{d}\right)^{p}\left(\frac{\sigma}{G}\right)^{n} \exp \left(-\frac{Q}{R T}\right)
$$

where $\dot{\varepsilon}$ is the strain rate, $A$ is a dimensionless constant, $G$ is the shear modulus, $b$ is the Burgers vector, $k$ is Boltzmann constant, $T$ is the temperature, $D_{0}$ is the frequency factor, $d$ is the grain size, $p$ is the exponent of the inverse grain size, $\sigma$ is the flow stress, $n$ is the stress exponent, $Q$ is the activation energy for the deformation and $R$ is the gas constant. For superplastic deformation, the strain rate sensitivity $m$ is conventionally used for $n$, where both parameters are related as $m=1 / n$.

The maximum flow stress is plotted against the initial strain rate in Fig. 9 in a double logarithmic form. Despite the data points are limited, they are well represented by a single straight line for each number of revolution. The slopes of the lines are $\sim 0.5$ for $N=10$ turns and $\sim 0.3$ for $N=2$ turns. The slope greater than $\sim 0.3$ is well consistent with the deformation mechanism controlled by grain boundary sliding. ${ }^{48)}$

To estimate $Q$, tensile tests were conducted at different temperatures in the range of $473 \mathrm{~K}$ to $723 \mathrm{~K}$ for the samples processed through $N=2$. Figure 10 shows the nominal flow stress delineated against elongation. The maximum flow stress normalized by $G$ as $(\sigma / G)$ is then plotted against the reciprocal temperature in Fig. 11 in a semi-logarithmic form. For this plot, temperature dependence of $G$ has been included using the relation as. ${ }^{49)}$
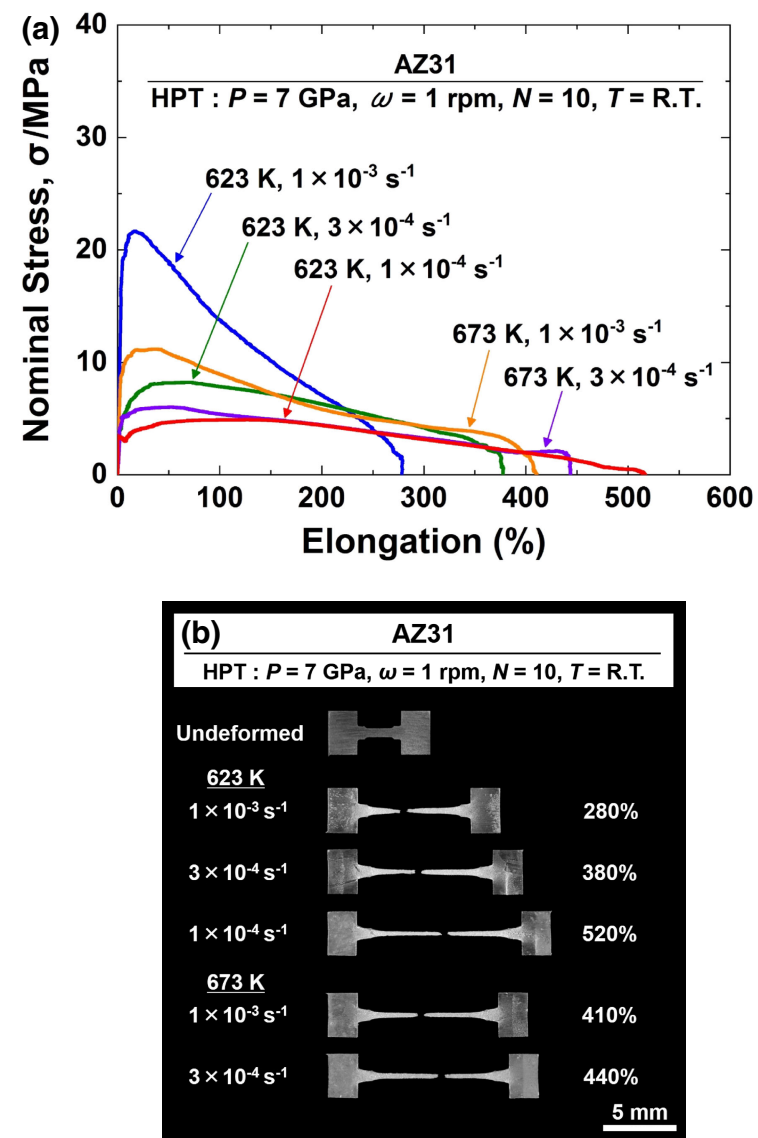

Fig. 7 (a) Nominal stress-elongation curves and (b) appearance of tensile specimens after deformation to failure for samples processed by HPT through 10 turns.

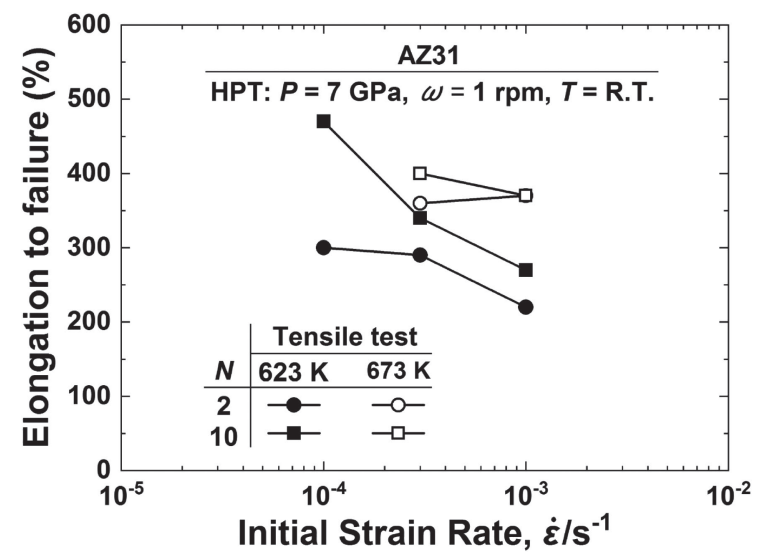

Fig. 8 Variations for elongation to failure with initial strain rate after tensile testing of samples processed by HPT through 2 and 10 turns.

$$
G=\left(1.92 \times 10^{4}-8.6 \times T\right) \mathrm{MPa}
$$

The slope in this plot corresponds to $m Q / R$ and thus, it follows that $Q=86 \mathrm{~kJ} / \mathrm{mol}$. Here, the value of $m=0.3$ has been used from the plot in Fig. 10 and the datum point from the tensile test at $473 \mathrm{~K}$ is excluded as its flow behavior does not represent superplasticity. The value of $Q=86$ $\mathrm{kJ} / \mathrm{mol}$ so obtained is very close to the activation energy for grain boundary diffusion in $\mathrm{Mg}(92 \mathrm{~kJ} / \mathrm{mol}) .{ }^{50)}$ It is thus concluded that the superplastic deformation in AZ31 occurs through grain boundary sliding controlled by grain boundary diffusion. 


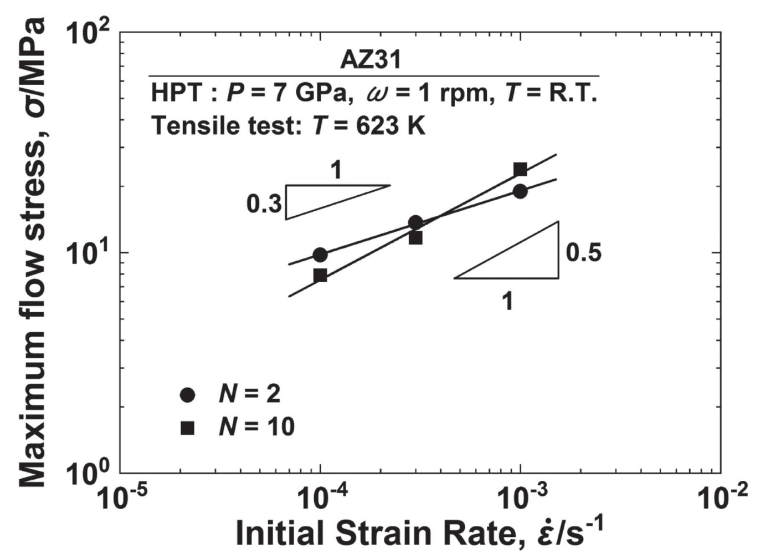

Fig. 9 Maximum flow stress plotted against initial strain rate for samples processed by HPT through 2 and 10 turns.

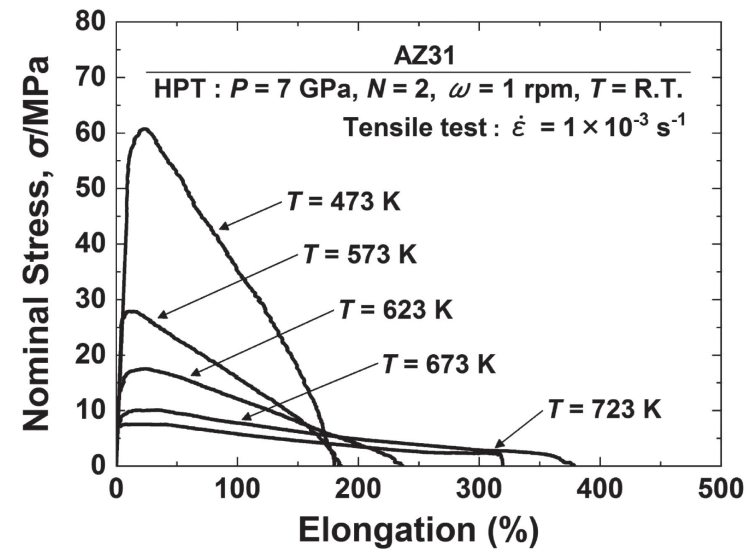

Fig. 10 Nominal stress-elongation curves after tensile testing at temperatures from 473 to $723 \mathrm{~K}$ with initial strain rate of $1 \times 10^{-3} \mathrm{~s}^{-1}$ for samples processed by HPT through 2 turns.

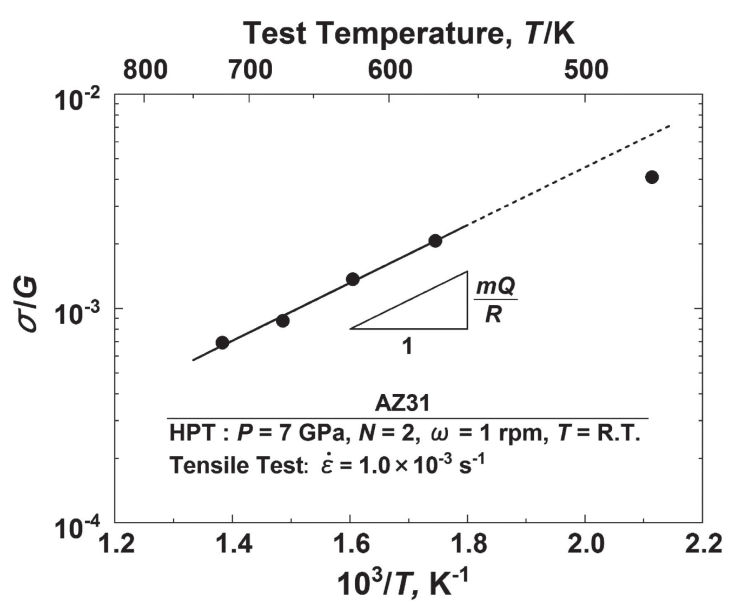

Fig. 11 Normalized stress plotted against reciprocal temperature for samples processed by HPT through 2 turns.

\subsection{Effect of surface roughness}

The present study shows the hardness-strain behavior typical of SPD-processed metallic materials ${ }^{44,45)}$ as plotted in Fig. 2(b), where the hardness is saturated at the equivalent strain beyond $\sim 80$. However, $\mathrm{Xu}$ et al. reported that the hardness saturation occurs at an equivalent strain of $\sim 20$. $^{40}$ ) In order to introduce a shear strain into the sample during

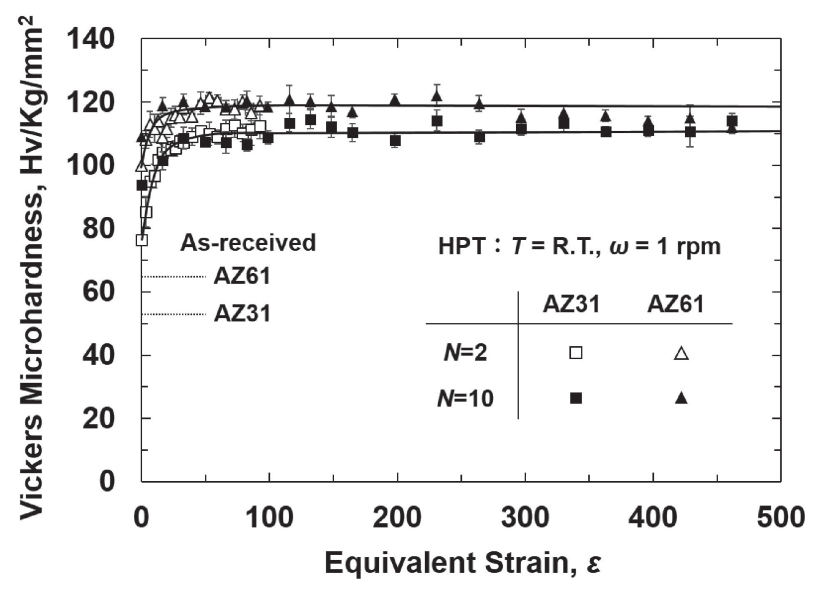

Fig. 12 Vickers microhardness plotted against equivalent strain for samples of AZ31 and AZ61 alloys processed by HPT through 2 and 10 turns.

HPT processing, it is important that the sample needs to be rigidly adhered on the anvils through frictional force between the sample and the anvil. If the adherence is not sufficient, slippage occurs between the sample and the anvils as reported by Edalati et al. ${ }^{51)}$ To increase the frictional force during HPT processing, the anvil surface needs to be carefully roughened. The anvils used for the AZ31 alloy in this study have surface roughness of $\mathrm{Ra}=\sim 10$ where $\mathrm{Ra}$ is defined as the arithmetic mean of the deviation from the average height in the roughness profile. The anvil surface was further roughened to $\mathrm{Ra}=\sim 15$ and, as shown in Fig. 12, the onset of the hardness saturation is shifted to the lower equivalent strain as $\sim 30$, while the level of the hardness saturation remains almost the same $(\sim 111 \mathrm{Hv})$. It is noted that this roughened anvil is used for the following AZ61 alloy.

\subsection{Hardness variation and microstructure of AZ61 alloy}

Figure 12 also shows the variations of Vickers microhardness for the AZ61 alloy as a function of the equivalent strain after processing for $N=2$ and 10 turns under $6 \mathrm{GPa}$ at room temperature. Figure 12 includes the initial hardness levels corresponding to the as-extruded conditions. A hardnessstrain behavior similar to AZ31 alloy is obtained, and now for the AZ61 alloy, the hardness saturation reaches at an equivalent strain of $\sim 20$ with the saturated level of $118 \mathrm{Hv}$ which is almost twice as high as the initial as-received state.

TEM micrographs with a bright-field image (left) and a dark-field image (right) including a SAED pattern (center) are shown in Fig. 13 for AZ61 alloy processed by HPT for 10 turns. Figure 13 clearly shows that an ultrafine-grained structure formed with equiaxed grains having a size reduced to $\sim 100 \mathrm{~nm}$. Harai et $a l .{ }^{42)}$ reported the average grain size of $\sim 110 \mathrm{~nm}$ after HPT processing for 5 turns using $10 \mathrm{~mm}$ diameter disks. Therefore, it is concluded that the microstructure for scaled-up samples are successfully refined to a well submicrometer level by the HPT processing.

\subsection{Tensile testing}

As schematically illustrated in Fig. 1(b), the dimensions of the tensile specimens including gripping parts are $3 \mathrm{~mm}$ width and $7 \mathrm{~mm}$ length. Hence, an only one tensile specimen 


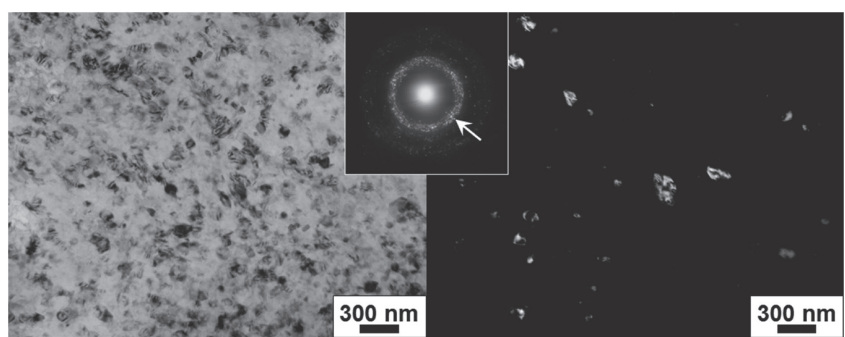

Fig. 13 TEM bright-field images (left), dark-field images (right) and selected area electron diffraction (SAED) patterns (inset) after HPT processing through 10 turns. Arrows in SAED patterns indicate beams for dark-field imaging.

can be taken at the pre-designated position which is $2 \mathrm{~mm}$ from the disk center in the conventional $10 \mathrm{~mm}$ disk sample due to its limited size. By contrast, multiple numbers of tensile specimens are able to be extracted along the radial direction as illustrated in Fig. 1(a). Figure 14 shows the results of the tensile tests after deformation at $473 \mathrm{~K}$ with the initial strain rate of $1.0 \times 10^{-3} \mathrm{~s}^{-1}$ for the AZ61 alloy where the tensile specimens were extracted at positions of $r=4,8$ and $12 \mathrm{~mm}$ after processing by HPT through 2 and 10 turns. The nominal flow stress is delineated against elongation in Fig. 14(a) and the appearance after specimen failure including the one before tensile deformation is shown in Fig. 14(b). The total elongation to failure is higher in the samples processed for $N=10$ turns than for $N=2$ turns as far as the distance from the center is the same. The total elongation tends to increase with increasing the radial distance. Both trends are consistent with the earlier report that, as the strain is more imposed, the total elongation increased. This is reasonable because an ultrafine-grained structure with high-angle grain boundaries are developed with increasing the strain. ${ }^{52)}$ The maximum superplastic elongation of $\sim 550 \%$ is achieved at $12 \mathrm{~mm}$ from the disk center for the sample after 10 turns. These results are summarized in Fig. 14(c) where the total elongations to failure are plotted against the equivalent strain. Figure 14(c) clearly shows a good relationship between the total elongation and the imposed strain and thereby it is suggested that the superplastic elongation of $\sim 400 \%$ may be attained at the equivalent strain beyond $\sim 210$ for the AZ61 alloy processed by HPT at room temperature. These tensile results demonstrate that upsizing the disk sample has advantage in evaluating mechanical properties especially for HPT processing whose sample size is generally small as compared to other SPD processes.

\section{Summary and Conclusions}

1. Facility of high-pressure torsion (HPT) was up-scaled to a maximum capacity of $5 \mathrm{MN}$ (500 ton) and a $30 \mathrm{~mm}$ diameter disk of two AZ series Mg alloys, AZ31 and AZ61, were successfully processed at room temperature under an imposed pressure of 6 to $7 \mathrm{GPa}$. The grain refinement was then feasible without causing any breaking or cracking of the AZ31 and AZ61 disks.

2. Transmission electron microscopy (TEM) revealed that the grain size was significantly reduced from $\sim 15 \mu \mathrm{m}$
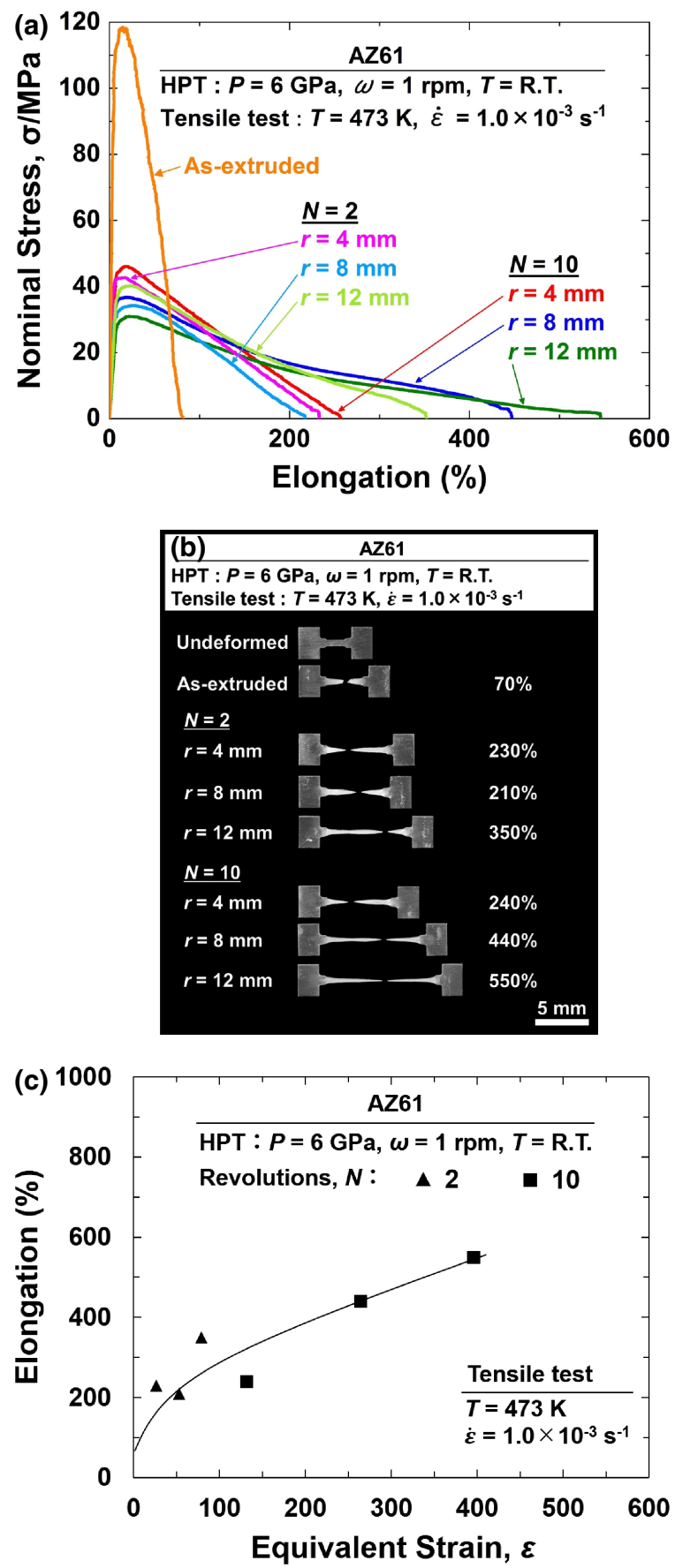

Fig. 14 (a) Nominal stress-elongation curves and (b) appearance of tensile specimens, and (c) summary of elongation to failure after deformation with initial strain rate of $1 \times 10^{-3} \mathrm{~s}^{-1}$ at $473 \mathrm{~K}$ for samples of AZ61 alloy processed by HPT through 2 and 10 turns.

and $\sim 34 \mu \mathrm{m}$ at the initial as-received states to $\sim 150 \mathrm{~nm}$ and $\sim 100 \mathrm{~nm}$, respectively, for the AZ31 alloy and the AZ61 alloy at the saturated state after the HPT processing.

3. Tensile testing showed that superplasticity with total elongations exceeding 300\% and 400\% were attained for the tensile specimens of the AZ31 alloy processed through equivalent strain of 90 and 450 (after $N=2$ and 10 turns), respectively. The largest elongation achieved in this study was $\sim 520 \%$ after tensile testing at $623 \mathrm{~K}$ with an initial strain rate of $1 \times 10^{-4} \mathrm{~s}^{-1}$. 
Evaluation of the deformation behavior concluded that the superplastic deformation occurs through grain boundary sliding controlled by grain boundary diffusion.

4. It is shown that the surface roughness of the anvils used for the HPT processing significantly affects the induced strain. The reasonable hardness-strain behaviors were obtained in both AZ31 and AZ61 alloys by roughening the anvil surface to $\mathrm{Ra}=\sim 15$.

5. Upsizing of the disk sample to a $30 \mathrm{~mm}$ diameter in HPT processing allows extraction of tensile specimens at three radial distances, 4,8 , and $12 \mathrm{~mm}$, from the disk center to evaluate the effect of the imposed strain on the superplastic elongation.

\section{Acknowledgements}

One of the authors (TM) would like to thank Grant-in-Aid for JSPS Research Fellow (No. JP16J07050) and the Aluminium Research Grant Program of Japan Aluminium Association. This work was supported in part by the Light Metals Educational Foundation of Japan, and in part by Grant-in-Aid for Scientific Research (S) from the MEXT, Japan (No. JP26220909). HPT was carried out in the International Research Center on Giant Straining for Advanced Materials (IRC-GSAM) at Kyushu University.

\section{REFERENCES}

1) R.Z. Valiev, R.K. Islamgaliev and I.V. Alexandrov: Prog. Mater. Sci. 45 (2000) 103-189.

2) R.Z. Valiev, Y. Estrin, Z. Horita, T.G. Langdon, M.J. Zehetbauer and Y.T. Zhu: JOM 58 (2006) 33-39.

3) P.W. Bridgman: Phys. Rev. 48 (1935) 825-847.

4) A.P. Zhilyaev and T.G. Langdon: Prog. Mater. Sci. 53 (2008) 893-979.

5) K. Edalati and Z. Horita: Mater. Sci. Eng. A 652 (2016) 325-352.

6) T. Waitz, V. Kazykhanov and H.P. Karnthaler: Acta Mater. 52 (2004) 137-147.

7) J.Y. Huang, Y.T. Zhu, X.Z. Liao and R.Z. Valiev: Philos. Mag. Lett. 84 (2004) 183-190.

8) C. Rentenberger, T. Waitz and H.P. Karnthaler: Mater. Sci. Eng. A 462 (2007) 283-288.

9) C. Mangler, C. Gammer, H.P. Karnthaler and C. Rentenberger: Acta Mater. 58 (2010) 5631-5638.

10) K. Edalati, S. Toh, H. Iwaoka, M. Watanabe, Z. Horita, D. Kashioka, K. Kishida and H. Inui: Scr. Mater. 67 (2012) 814-817.

11) K. Edalati, J. Matsuda, H. Iwaoka, S. Toh, E. Akiba and Z. Horita: Int. J. Hydrogen Energy 38 (2013) 4622-4627.

12) R.K. Islamgaliev, R. Kuzel, S.N. Mikov, A.V. Igo, J. Burianek, F. Chmelik and R.Z. Valiev: Mater. Sci. Eng. A 266 (1999) 205-210.

13) Y. Ikoma, K. Hayano, K. Edalati, K. Saito, Q. Guo and Z. Horita: Appl. Phys. Lett. 101 (2012) 121908.

14) Y. Ikoma, K. Hayano, K. Edalati, K. Saito, Q. Guo, Z. Horita, T. Aoki and D.J. Smith: J. Mater. Sci. 49 (2014) 6565-6569.

15) Y. Ikoma, Y. Ejiri, K. Hayano, K. Saito, Q. Guo and Z. Horita: Philos. Mag. Lett. 94 (2014) 1-8.

16) S. Harish, M. Tabara, Y. Ikoma, Z. Horita, Y. Takata, D.G. Cahill and M. Kohno: Nanoscale Res. Lett. 9 (2014) 326.

17) Y. Ikoma, K. Kumano, K. Edalati, K. Saito, Q. Guo and Z. Horita: Philos. Mag. Lett. 97 (2017) 27-34.

18) Y. Fukushima, Y. Ikoma, K. Edalati, B. Chon, D.J. Smith and Z. Horita: Mater. Charact. 129 (2017) 163-168.

19) Y. Ikoma, K. Kumano, K. Edalati, M.R. McCartney, D.J. Smith and Z.
Horita: Mater. Charact. 132 (2017) 132-138.

20) K. Edalati and Z. Horita: Scr. Mater. 63 (2010) 174-177.

21) K. Edalati, S. Toh, Y. Ikoma and Z. Horita: Scr. Mater. 65 (2011) 974 977.

22) K. Edalati, M. Arimura, Y. Ikoma, T. Daio, M. Miyata, D.J. Smith and Z. Horita: Mater. Res. Lett. 3 (2015) 216-221.

23) H. Razavi-Khosroshahi, K. Edalati, M. Arita, Z. Horita and M. Fuji: Scr. Mater. 124 (2016) 59-62.

24) H. Razavi-Khosroshahi, K. Edalati, M. Hirayama, H. Emami, M. Arita, M. Yamauchi, S. Ida, T. Ishihara, E. Akiba, Z. Horita and M. Fuji: ACS Catal. 6 (2016) 5103-5107.

25) H. Razavi-Khosroshahi, K. Edalati, H. Emami, E. Akiba, Z. Horita and M. Fuji: Inorg. Chem. 56 (2017) 2576-2580.

26) K. Edalati, H. Iwaoka, S. Toh, K. Sasaki and Z. Horita: Mater. Trans. 54 (2013) 1540-1548.

27) A. Alhamidi, K. Edalati, H. Iwaoka and Z. Horita: Philos. Mag. 94 (2014) 876-887.

28) S. Lee, K. Edalati, H. Iwaoka, Z. Horita, T. Ohtsuki, T. Ohkochi, M. Kotsugi, T. Kojima, M. Mizuguchi and K. Takanashi: Philos. Mag. Lett. 94 (2014) 639-646.

29) K. Edalati, H. Emami, Y. Ikeda, H. Iwaoka, I. Tanaka, E. Akiba and Z. Horita: Acta Mater. 108 (2016) 293-303.

30) K. Edalati, R. Uehiro, K. Fujiwara, Y. Ikeda, H.W. Li, X. Sauvage, R.Z. Valiev, E. Akiba, I. Tanaka and Z. Horita: Mater. Sci. Eng. A 701 (2017) 158-166.

31) K. Edalati, Z. Horita and T.G. Langdon: Scr. Mater. 60 (2009) 9-12.

32) H.K. Lin and J.C. Huang: Mater. Trans. 43 (2002) 2424-2432.

33) K. Xia, J.T. Wang, X. Wu, G. Chen and M. Gurvan: Mater. Sci. Eng. A 410-411 (2005) 324-327.

34) M. Eddahbi, J.A. del Valle, M.T. Perez-Prado and O.A. Ruano: Mater. Sci. Eng. A 410-411 (2005) 308-311.

35) J. Xing, X. Yang, H. Miura and T. Sakai: Mater. Trans. 48 (2007) 14061411.

36) M. Al-Maharbi, I. Karaman, I.J. Beyerlein, D. Foley, K.T. Hartwig, L.J. Kecskes and S.N. Mathaudhu: Mater. Sci. Eng. A 528 (2011) 76167627.

37) D. Zhang, F. Xiong, W. Zhang, C. Qiuw and W. Zhang: Trans. Nonferrous Met. Soc. China 21 (2011) 1911-1916.

38) X. Wang, M. Wu, W. Ma, Y. Lu and S. Yuan: J. Mater. Eng. Perform. 25 (2016) 64-67.

39) Y. Huang, R.B. Figueredo, T. Baudin, A. Helbert, F. Brisset and T.G. Langdon: J. Mater. Sci. 47 (2012) 7796-7806.

40) J. Xu, X. Wang, M. Shirooyeh, G. Xing, D. Shan, B. Guo and T.G. Langdon: J. Mater. Sci. 50 (2015) 7424-7436.

41) J. Stráská, M. Janeček, J. Gubicza, T. Krajňák, E.Y. Yoon and H.S. Kim: Mater. Sci. Eng. A 625 (2015) 98-106.

42) Y. Harai, M. Kai, K. Kaneko, Z. Horita and T.G. Langdon: Mater. Trans. 49 (2008) 76-83.

43) It is important that the dimensions of the tensile specimens particularly at the gauge part affect the total elongation to failure. While $\mathrm{Xu}$ et al. and Harai et al. used the tensile specimens with $1 \mathrm{~mm}$ length, $1 \mathrm{~mm}$ width and $0.6 \mathrm{~mm}$ thickness at the gauge part, this study used $1.5 \mathrm{~mm}$ length, $0.6 \mathrm{~mm}$ width and $0.7 \mathrm{~mm}$ thickness as shown in Fig. 1(b). Because longer gauge length leads to less elongation to failure, the comparison with the past reports is promising to demonstrate the advantage of the upsized samples in this study.

44) K. Edalati and Z. Horita: Mater. Trans. 51 (2010) 1051-1054.

45) K. Edalati, D. Akama, A. Nishio, S. Lee, Y. Yonenaga, J.M. CuberoSesin and Z. Horita: Acta Mater. 69 (2014) 68-77.

46) J.W. Edington, K.N. Melton and C.P. Cutler: Prog. Mater. Sci. 21 (1976) 61-170.

47) O.D. Sherby and J. Wadsworth: Prog. Mater. Sci. 33 (1989) 169-221.

48) T.G. Langdon: Acta Metall. Mater. 42 (1994) 2437-2443.

49) S.S. Vagarali and T.G. Langdon: Acta Metall. 29 (1981) 1969-1982.

50) H.J. Frost and M.F. Ashby: Deformation Mechanism Maps, (Pergamon Press, Oxford, 1982).

51) K. Edalati, Z. Horita and T.G. Langdon: Scr. Mater. 60 (2009) 9-12.

52) Y. Ito and Z. Horita: Mater. Sci. Eng. A 503 (2009) 32-36. 